\title{
BRAFV600E mutation in papillary thyroid microcarcinoma: a meta-analysis
}

\author{
Fei $\mathrm{Li}^{1,2,3,{ }^{*}, \text { Guangqi Chen }}{ }^{4,}$, Chunjun Sheng', Aaron M Gusdon ${ }^{5}$, Yueye Huang', \\ Zhongwei $\mathrm{Lv}^{6,8}$, Huixiong $\mathrm{Xu}^{7,8}$, Mingzhao $\mathrm{Xing}^{8,9}$ and Shen $\mathrm{Qu}^{1,2,8}$ \\ 1Department of Endocrinology, Shanghai Tenth People's Hospital, Tongji University School of Medicine, \\ 301 Yan Chang Middle Road, Shanghai 200072, China \\ ${ }^{2}$ First Clinical Medical College, Nanjing Medical University, Nanjing 210029, China \\ ${ }^{3}$ Jiangsu Institute of Nuclear Medicine, Wuxi 214063, China \\ ${ }^{4}$ Department of Cardiology, Shanghai Tenth People's Hospital, Tongji University School of Medicine, \\ Shanghai 200072, China \\ ${ }^{5}$ Department of Neurology and Neuroscience, Weill Cornell Medical College, New York, New York 10065, USA \\ Departments of ${ }^{6}$ Nuclear Medicine, and ${ }^{7}$ Ultrasound Medicine, Shanghai Tenth People's Hospital, \\ Shanghai 200072, China \\ ${ }^{8}$ Thyroid Institute, Tongji University, Shanghai 200072, China \\ ${ }^{9}$ Division of Endocrinology, Diabetes and Metabolism, The Johns Hopkins University School of Medicine, \\ Baltimore, Maryland 21287, USA \\ *(F Li and G Chen contributed equally to this work and should be considered co-first authors)
}

\author{
Correspondence \\ should be addressed \\ to S Qu \\ Email \\ qushencn@hotmail.com
}

\begin{abstract}
The prognostic value of the BRAFV600E mutation, resulting in poor clinical outcomes of papillary thyroid carcinoma, has been generally confirmed. However, the association of BRAFV600E with aggressive clinical behaviors of papillary thyroid microcarcinoma (PTMC) has not been firmly established in individual studies. We performed this meta-analysis to examine the relationship between BRAFV600E mutation and the clinicopathological features of PTMC. We conducted a systematic search in PubMed, EMBASE, and the Cochrane library for relevant studies. We selected all the studies that reported clinicopathological features of PTMC patients with information available on BRAFV600E mutation status. Nineteen studies involving a total of 3437 patients met these selection criteria and were included in the analyses. The average prevalence of the BRAFV600E mutation was $47.48 \%$, with no significant difference with respect to patient sex (male versus female) and age (younger than 45 years versus 45 years or older). Compared with the WT BRAF gene, the BRAFV600E mutation was associated with tumor multifocality (odds ratio (OR) $1.38 ; 95 \% \mathrm{Cl}$, 1.04-1.82), extrathyroidal extension (OR 3.09; $95 \% \mathrm{Cl}, 2.24-4.26)$, lymph node metastases (OR 2.43; $95 \% \mathrm{Cl}, 1.28-4.60$ ), and advanced stage (OR 2.39; $95 \% \mathrm{Cl}, 1.38-4.15$ ) of PTMC. Thus, our findings from this large meta-analysis definitively demonstrate that BRAFV600Emutation-positive PTMC are more likely to manifest with aggressive clinicopathological characteristics. In appropriate clinical settings, testing for the BRAFV600E mutation is likely to be useful in assisting the risk stratification and management of PTMC.
\end{abstract}

\footnotetext{
Key Words

- BRAFV600E mutation

- thyroid cancer

- papillary thyroid microcarcinoma

- meta-analysis

- prognosis
}

Endocrine-Related Cancer (2015) 22, 159-168
(C) 2015 Society for Endocrinology Printed in Great Britain
Published by Bioscientifica Ltd 


\section{Introduction}

A papillary thyroid carcinoma (PTC) measuring $\leq 1.0 \mathrm{~cm}$ or less in size is defined as papillary thyroid microcarcinoma (PTMC) by the World Health Organization Histological Classification of Tumors, and is often an incidental finding on histopathologic examination after thyroid surgery (LiVolsi et al. 2004). Owing to the widespread application of high-resolution thyroid ultrasound (US) and US-guided fine-needle aspiration biopsy (FNAB), PTC has been increasingly discovered at early stages in recent years. PTMC thus has become the most common form of PTC, accounting for almost half of all PTCs in large series reported in recent years (Davies \& Welch 2006). According to the United States' Surveillance, Epidemiology, and End Results (SEER) data, the proportion of PTMC patients among all PTC cases has been rising rapidly since the 1980s; for example, it rose from 30\% in 1988 to $40 \%$ in 2003 (Ries et al. 2007). The clinical management of patients with PTMCs, however, remains variable and controversial, because these tumors generally have a clinically indolent and innocuous course with excellent clinical prognosis. Some cases of PTMC, however, do exhibit aggressive clinicopathological characteristics and poor clinical outcomes (Roti et al. 2008). Therefore, identification of markers capable of distinguishing these aggressive tumors, especially in the phase before surgery, would be very useful in guiding appropriate clinical management of PTMC.

The BRAFV600E mutation, a point mutation at codon 600 of BRAF, results in substitution of valine to glutamate (V600E), leading to constitutive activation of the BRAF kinase and consequent uncontrolled activation of the MAPK pathway signaling (Davies et al. 2002). It is the most common genetic event in PTC and has been identified in about $45 \%$ of PTC cases and $25 \%$ of anaplastic thyroid cancer; but it does not occur in other thyroid cancers and benign tumors (Xing 2005, 2007). PTMCs have also been shown to harbor BRAFV600E mutations, which are considered to be the early stage of PTCs (de Biase et al. 2014). In recent years, the BRAFV600E mutation has emerged as a highly specific diagnostic marker and a useful prognostic factor in the risk stratification of PTC (Xing 2007). Results from many studies have indicated that BRAFV600E mutation is significantly associated with aggressive clinicopathological features of PTC, such as multifocality, extrathyroid extension, lymph node metastases (LNMs) at presentation, and advanced stage (Xing 2007, Mathur et al. 2010, Moses et al. 2010). Recent large meta-analyses of studies on general PTC re-confirmed the association of the BRAFV600E mutation with prognostic factors and poor clinical outcomes of PTCs (Kim et al. 2012, Tufano et al. 2012). However, the value of the BRAFV600E mutation as a prognostic marker in PTMC is not entirely clear, although PTMC also belongs to the well-differentiated papillary carcinoma group. Results from some individual studies indicated that BRAFV600E mutation was significantly correlated with more aggressive characteristics of PTMCs (Lupi et al. 2007, Lee et al. 2009, Lin et al. 2010, Kurtulmus et al. 2012), while others did not show such a relationship (Kim et al. 2005, Kwak et al. 2009, Choi et al. 2013). A major limitation of these latter studies is the limited numbers of patients with PTMC. Thus, additional studies including larger numbers of patients are needed to determine whether the presence of the BRAFV600E mutation is a prognostic factor for patients with PTMC. To this end, we performed a comprehensive meta-analysis on a large number of patients to further examine the relationship between the BRAFV600E mutation and the clinicopathological features of PTMC.

\section{Materials and methods}

\section{Search strategy and selection criteria}

We searched PubMed, EMBASE, and the Cochrane Library databases to identify all potential clinical studies published before January 2014 that reported on BRAFV600E and aggressive clinical behaviors of PTMC. The following search terms were employed: PTMC, thyroid microcarcinoma, papillary microcarcinoma of the thyroid, micropapillary thyroid cancer, papillary microcarcinoma, and BRAF. In addition to the primary electronic search, we also reviewed the related citations in PubMed and examined the references of retrieved articles for any relevant articles. We screened and selected pertinent articles for inclusion by using the software EndNote X6 (Thomson Reuters (Scientific), Inc., Midtown Manhattan, New York, NY, USA). Any studies that reported the clinicopathological features of PTMC patients with information available on BRAFV600E mutation status were considered for inclusion. If a study reported data on both PTMC and PTC $>1.0 \mathrm{~cm}$, only the former were used. The authors independently assessed articles for eligibility by screening all titles and abstracts and reviewing the full text of potentially relevant studies according to predefined inclusion and exclusion criteria. Any article was excluded i) if it only enrolled thyroid cancer subjects with tumor

Published by Bioscientifica Ltd 


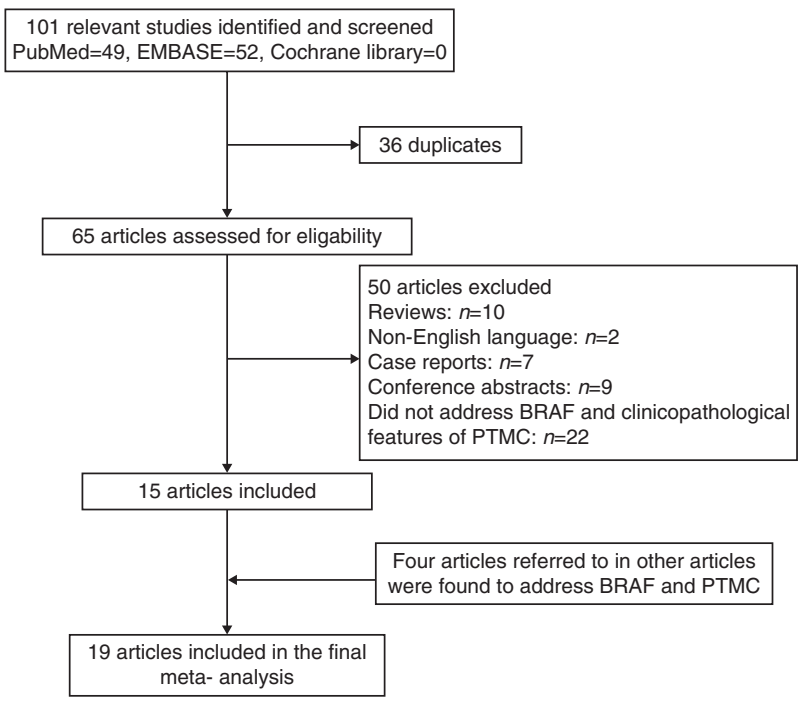

Figure 1

The search strategy.

diameter $>1.0 \mathrm{~cm}$; ii) if it did not report any clinicopathological factors of the PTMC subjects (e.g., sex, age, multifocality, LNMs, extrathyroidal extension, and advanced stage); iii) if no $B R A F$ mutation information was reported; iv) if it did not include PTMC defined by the WHO criteria; v) if only selected disease stages or only selected characteristics of PTMC were reported; and vi) if the study was published as an abstract, expert opinion, letter, conference article, editorial, case report, or review. When several papers were found analyzing the same population, only the most relevant was included. Only studies reported in English were included. Final selection of an eligible article was determined by consensus of the authors based on the above inclusion and exclusion criteria. Figure 1 summarizes the search strategy.

\section{Data extraction}

We extracted the following information from each study: the first author, year of publication, country, number of participants, patient sex and age, clinicopathological features (including multifocality, LNMs, extrathyroidal extension, and tumor stages), BRAFV600E mutation status, BRAFV600E mutation sequencing method, and sample source.

\section{Data analyses and statistical methods}

Statistical analysis was conducted using Stata software version 12.0 (StataCorp., College Station, TX, USA). The occurrence of BRAFV600E was treated as a dichotomous variable and discrepancies between groups divided by clinicopathological factors were presented as odds ratios (ORs) with 95\% CI, which were calculated using the Mantel-Haenszel method. Heterogeneity among the studies was tested using $I^{2}$ statistics, which are a quantitative tool of variability across studies. An $I^{2}$ value of 25,50 , and $75 \%$ indicates low, moderate, and high heterogeneity respectively (Higgins et al. 2003). We used a random effects model to synthesize the outcomes. To examine the robustness of the outcomes, we also performed sensitivity and subgroup analyses when heterogeneity was evident.

\section{Results}

The basic characteristics of the eligible studies are summarized in Table 1. Nineteen studies (Kim et al. 2005, Lupi et al. 2007, Rodolico et al. 2007, Frasca et al. 2008, Min etal. 2008, Kwak etal. 2009, Lee et al. 2009, Basolo et al. 2010, Jung et al. 2010, Lin et al. 2010, Kurtulmus et al. 2012, Marchetti et al. 2012, Schulten et al. 2012, Choi et al. 2013, Chung et al. 2013, Mussazhanova et al. 2013, Rossi et al. 2013, Virk et al. 2013, Zheng et al. 2013), including 3437 patients, fulfilled the eligibility criteria and were included in the meta-analysis. Overall, $1632(47.48 \%)$ of these patients had BRAFV600E-mutation-positive PTMCs. Sample sizes of these studies ranged from 13 to 977 patients. The earliest study was published in November 2005 and the most recent study was published in July 2013. Not all of the studies had all of the variables of our interest and some studies contained variables not needed for this analysis. Therefore, for each study, we only analyzed data for the relevant variables. Virtually all of the included studies were retrospective studies. Four studies established BRAF status from FNAC materials, 11 studies from paraffin-embedded tissues, and the rest used a mixture of FNAC and paraffinembedded tissues.

\section{Sex}

Eight studies (Kim et al. 2005, Kwak et al. 2009, Lee et al. 2009, Basolo et al. 2010, Choi et al. 2013, Mussazhanova et al. 2013, Virk et al. 2013, Zheng et al. 2013), involving 456 male and 1800 female patients, were analyzed for the association between BRAFV600E mutation and patient sex. BRAFV600E mutation was detected in 235 (51.54\%) of the 456 male and $819(45.50 \%)$ of the 1800 female PTMC patients. No significant association was found between sex and BRAFV600E mutation (Fig. 2; OR 1.36; 95\% CI, 0.98-1.90). The heterogeneity among the studies was low $\left(I^{2}=30.6 \%\right)$.

Published by Bioscientifica Ltd 
Table 1 Characteristics of the included studies

\begin{tabular}{|c|c|c|c|c|c|c|c|}
\hline \multirow[b]{2}{*}{ Study } & \multirow[b]{2}{*}{ Country } & \multirow{2}{*}{$\begin{array}{l}\text { No. of } \\
\text { cases }\end{array}$} & \multirow[b]{2}{*}{$\operatorname{Sex}(F / M)$} & \multirow{2}{*}{$\begin{array}{l}\text { Mean age } \\
\text { (years) }\end{array}$} & \multicolumn{3}{|c|}{ BRAFV600E mutation } \\
\hline & & & & & Sample & Method & No. $(\%)$ \\
\hline Kim et al. (2005) & Korea & 60 & $56 / 4$ & $46.3 \pm 10.2$ & FFPE tissues & $\mathrm{Sq}$ & $31(51.67)$ \\
\hline Rodolico et al. (2007) & USA & 214 & $171 / 43$ & $41.3 \pm 9.9$ & FFPE tissues & ASA & $88(41.12)$ \\
\hline Lupi et al. $(2007)^{a}$ & Italy & 230 & $171 / 59$ & $46.1 \pm 12.7$ & FFPE tissues & $\mathrm{SSCP}$ and $\mathrm{Sq}$ & $90(39.13)$ \\
\hline Min et al. (2008) & Korea & 60 & NA & NA & FFPE tissues & SSCP & $32(53.33)$ \\
\hline Frasca et al. (2008) & Italy & 103 & NA & NA & FFPE tissues & $\mathrm{Sq}$ & $25(24.27)$ \\
\hline Lee et al. (2009) & China & 64 & $56 / 8$ & $46.6 \pm 11.0$ & $\begin{array}{l}\text { FFPE tissue }(n=40) \\
\text { fresh tissue } \\
(n=24)\end{array}$ & $\mathrm{Sq}$ & $24(37.5)$ \\
\hline Kwak et al. (2009) & Korea & 339 & $295 / 44$ & 45.4 & FNAC & $\mathrm{Sq}$ & $213(62.83)$ \\
\hline Basolo et al. $(2010)^{a}$ & Italy & 578 & $435 / 143$ & $<45,48.09 \%$ & FFPE tissues & SSCP and Sq & $229(39.62)$ \\
\hline Jung et al. (2010) & Korea & 147 & $126 / 21$ & $<45,39 \%$ & FFPE tissues & $\mathrm{Sq}$ & $110(74.83)$ \\
\hline Lin et al. (2010) & China & 61 & $52 / 9$ & $49.0 \pm 12.4$ & FNAC & $\mathrm{Sq}$ & $21(34.43)$ \\
\hline Marchetti et al. (2012) & Italy & 85 & NA & NA & FNAC & $\mathrm{Sq}$ & $63(74.12)$ \\
\hline Kurtulmus et al. (2012) & Turkey & 64 & NA & $38.7 \pm 9.9$ & FFPE tissues & FMCA & $19(29.69)$ \\
\hline Schulten et al. (2012) & Saudi Arabia & 56 & $48 / 8$ & $36.4 \pm 13.5$ & FFPE tissues, FNAC & $\mathrm{Sq}$ & $10(17.86)$ \\
\hline Rossi et al. (2013) & Italy & 50 & NA & NA & FNAC & $\mathrm{Sq}$ & $34(68)$ \\
\hline Choi et al. (2013) & Korea & 101 & $90 / 11$ & $<45,24.75 \%$ & FFPE tissues & $\mathrm{Sq}$ & 72 (71.29) \\
\hline Virk et al. (2013) & USA & 124 & $103 / 21$ & NA & $\begin{array}{l}\text { FNAC }(n=51), \text { FFPE } \\
\text { tissue }(n=78)\end{array}$ & SSCP & $87(70.16)$ \\
\hline Mussazhanova et al. (2013) & Japan & 13 & $11 / 2$ & $45.9 \pm 6.0$ & FFPE tissues & $\mathrm{Sq}$ & $6(46.15)$ \\
\hline Zheng et al. (2013) & China & 977 & $754 / 223$ & $45.95 \pm 10.5$ & FFPE tissues & $\mathrm{Sq}$ & $392(40.12)$ \\
\hline Chung et al. (2013) & Korea & 111 & $95 / 16$ & $47.9 \pm 13.6$ & $\begin{array}{l}\text { FNAC }(n=85), \text { FFPE } \\
\text { tissues }(n=26)\end{array}$ & Sq & $86(77.48)$ \\
\hline Total & 19 studies & 3437 & & & & & $1632(47.48)$ \\
\hline
\end{tabular}

FFPE, formalin-fixed, paraffin-embedded; FNAC, fine-needle aspiration cytology; Sq, sequencing; SSCP, single-strand conformational polymorphism; FMCA fluorescence melting curve analysis; ASA, allele-specific amplification; NA, not available.

an the two studies, the age at diagnosis of four patients from Lupi et al. (2007) and two patients from Basolo et al. (2010) was unknown.

${ }^{b}$ BRAFV600E mutational analysis was performed in 129 tumors from 124 patients.

Age

To assess the relationship between BRAFV600E mutation and age, patients were divided into two groups based on age, one younger than 45 years and the other 45 years or older. Six studies were available for this analysis (Kim et al. 2005, Lupi et al. 2007, Basolo et al. 2010, Choi et al. 2013, Mussazhanova et al. 2013, Zheng et al. 2013), involving 1953 patients. Of the 1071 patients of 45 years age or older, 423 (39.50\%) were BRAFV600E-mutationpositive, and 394 (44.67\%) of the 882 patients younger than 45 years were BRAFV600E-mutation-positive. The association between BRAFV600E and patient age is close to significance (Fig. 3; OR 0.78; 95\% CI, 0.60-1.00). The heterogeneity among the studies was low $\left(I^{2}=28.4 \%\right)$.

\section{Thyroid multifocality}

Ten studies (Kim et al. 2005, Lupi et al. 2007, Frasca et al. 2008, Kwak et al. 2009, Basolo et al. 2010, Lin et al. 2010, Kurtulmus et al. 2012, Marchetti et al. 2012, Choi et al. 2013, Zheng et al. 2013), including 2598 patients, were analyzed for the association between BRAFV600E Printed in Great Britain mutation and multifocality of PTMC. Of 1155 patients with BRAFV600E, 406 (35.15\%) had multifocal disease, whereas 448 (31.05\%) of the 1443 patients with WT BRAFV600E had multifocal disease. A significant association existed between the BRAFV600E mutation and multifocality (Fig. 4; OR 1.38; 95\% CI, 1.04-1.82).

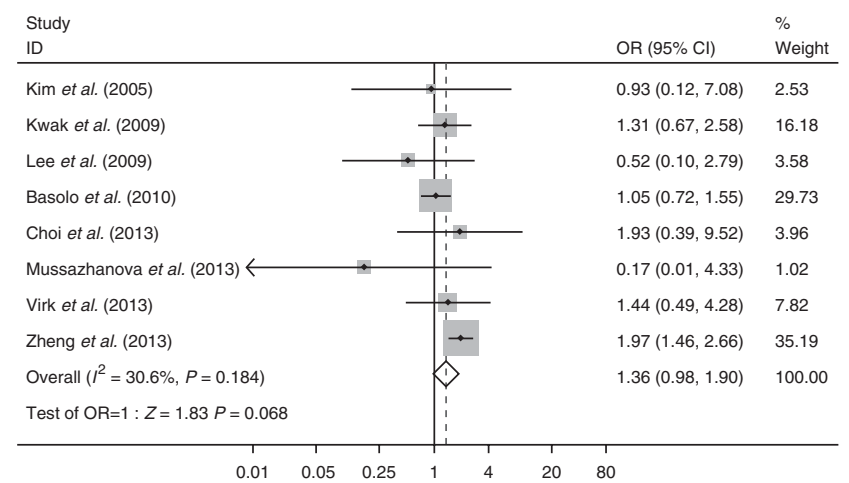

Figure 2

Random effect model of the odds ratios (ORs) with $95 \% \mathrm{Cl}$ of the frequency of BRAFV600E mutation associated with sex is shown.

Published by Bioscientifica Ltd. 


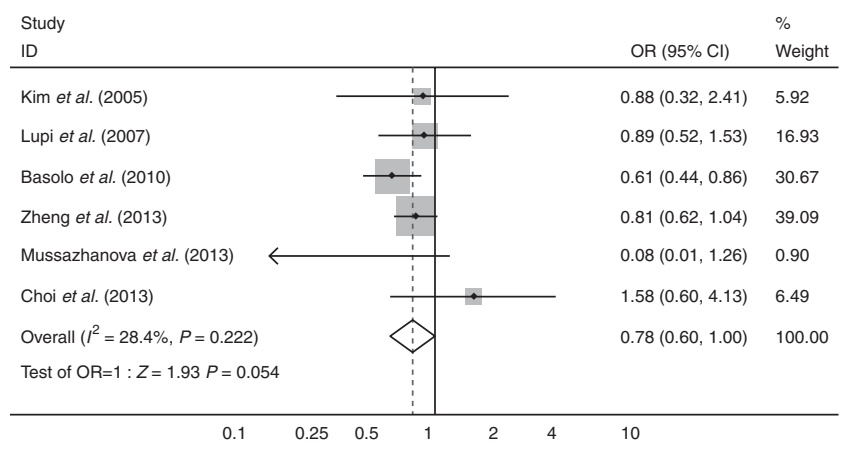

Figure 3

Random effect model of the odds ratios (ORs) with $95 \% \mathrm{Cl}$ of the frequency of BRAFV600E mutation associated with age is shown.

The heterogeneity of the data was not significant and the $I^{2}$ estimate of the variance between the studies was $45.4 \%$.

\section{Extrathyroidal extension}

Twelve studies (Kim et al. 2005, Lupi et al. 2007, Frasca et al. 2008, Lee et al. 2009, Basolo et al. 2010, Lin et al. 2010, Kurtulmus et al. 2012, Marchetti et al. 2012, Choi et al. 2013, Mussazhanova et al. 2013, Rossi et al. 2013, Zheng et al. 2013) involving 1006 patients with BRAFV600E and 1380 patients with WT BRAF were analyzed with regard to extrathyroidal extension. Extrathyroidal extension was detected in 393 (39.07\%) of the 1006 patients with BRAFV600E, and was detected in 213 (15.43\%) of the 1380 patients with WT BRAF. There was a significant association between BRAFV600E mutation and extrathyroidal extension (Fig. 5; OR 3.09; 95\% CI, 2.24-4.26). No significant statistical heterogeneity was found among the studies $\left(I^{2}=36.3 \%\right)$.

\section{Lymph node metastasis}

Seventeen studies (Kim et al. 2005, Lupi et al. 2007, Rodolico et al. 2007, Frasca et al. 2008, Min et al. 2008, Lee et al. 2009, Basolo et al. 2010, Jung et al. 2010, Lin et al. 2010, Kurtulmus et al. 2012, Marchetti et al. 2012, Choi et al. 2013, Chung et al. 2013, Mussazhanova et al. 2013, Rossi et al. 2013, Virk et al. 2013, Zheng et al. 2013) including 1385 cases with BRAFV600E and 1620 patients with WT BRAF were analyzed with regard to LNM. LNM was found in 486 (35.09\%) of 1385 cases with BRAFV600E and in $171(10.56 \%)$ of 1620 patients with WT BRAF. There was a significant association between BRAFV600E mutation and LNM (Fig. 6; OR 2.43; 95\% CI, 1.28-4.60). Significant statistical heterogeneity was found among the studies $\left(I^{2}=85.8 \%\right)$. Sensitivity analysis was performed and, as a result, the heterogeneity of the data markedly decreased to $41.3 \%$ when the study of Zheng et al. (2013) was excluded. We did not find any other major changes when sensitivity analysis was performed in other cases. Therefore, this study was a major contribution to the heterogeneity. With this treatment, a significant association still existed between BRAFV600E mutation and LNM after exclusion of this study (OR 1.94; 95\% CI, 1.35-2.79).

\section{Advanced stages}

Nine studies (Kim et al. 2005, Frasca et al. 2008, Kwak et al. 2009, Lee et al. 2009, Basolo et al. 2010, Lin et al. 2010, Schulten et al. 2012, Choi et al. 2013, Zheng et al. 2013) including 1017 patients with BRAFV600E and 1320 patients with WT BRAF were analyzed with regard to advanced stage of PTMC. Advanced stage (defined as TNM III/IV) was found in 356 (35.00\%) of the 1017 patients with mutant BRAF and in $213(16.14 \%)$ of the 1320 patients with WT BRAF. There was a significant association between BRAFV600E and advanced stage (Fig. 7; OR 2.39; 95\% CI, 1.38-4.15). Significant heterogeneity was found among the studies $\left(I^{2}=77.7 \%\right)$.

\section{Analyses of the effects of BRAFV600E mutation on the aggressive clinicopathological features of PTMC according to country}

Subgroup analysis was conducted according to the country of the study subjects to investigate the potential sources of heterogeneity and assess whether the effects of BRAFV600E on aggressive clinicopathological features of

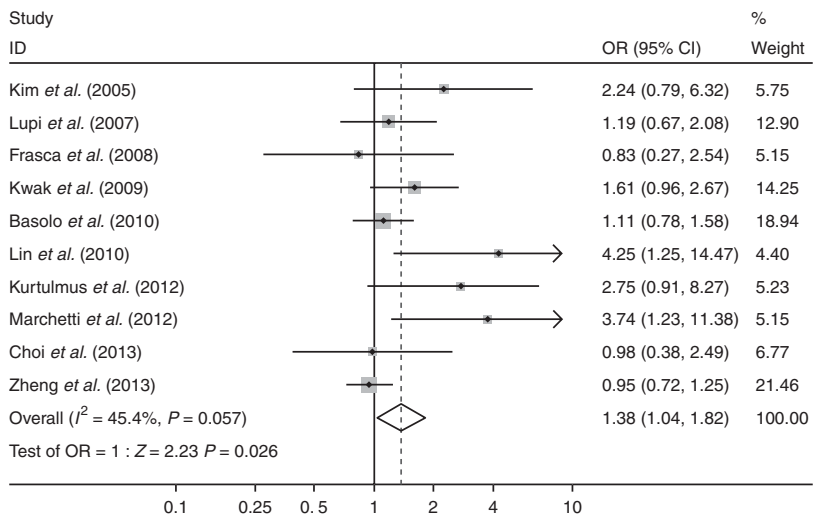

Figure 4

Random effect model of the odds ratios (ORs) with $95 \% \mathrm{Cl}$ of the BRAFV600E mutation associated with thyroid multifocality is shown.

Published by Bioscientifica Ltd 


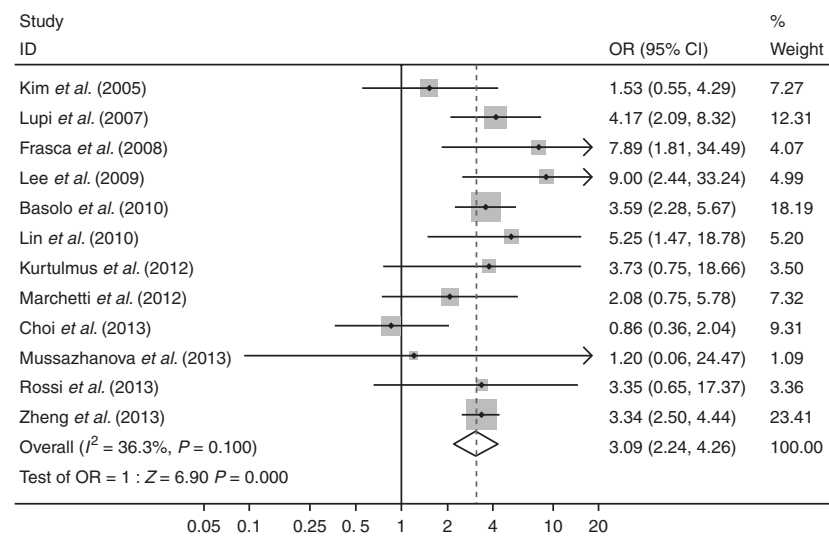

Figure 5

Random effect model of the odds ratios (ORs) with $95 \% \mathrm{Cl}$ of the BRAFV600E mutation associated with extrathyroidal extension is shown.

PTMC were associated with geographic regions (Table 2). The effect estimates were broadly consistent among the subgroups that were analyzed. The heterogeneity was significantly decreased in the subgroup analysis of extrathyroidal extension and advanced stage. However, the results of the subgroup analyses also indicated that BRAFV600E is not significantly associated with high-risk tumor features (e.g., extra-thyroidal extension, LNM, and advanced stage) of PTMC in patients from Korea, where the prevalence of the BRAFV600E mutation was unusually high. It is also notable that the Korean subgroup has a significant odds ratio for tumor multimodality, while the other geographical subgroups do not.

\section{Discussion}

In recent decades, the incidence of thyroid cancer, especially that of PTMC, has been rapidly rising (Davies \& Welch 2006). In the United States, it has been reported that PTMC is the most common thyroid malignancy in patients older than the age of 45 years (Hughes et al. 2011). Therefore, it has become a major challenge to appropriately manage the increasing number of PTMC cases. PTMCs seem to consist of two biologically distinct subpopulations: a population with indolent tumors that have minimal or no potential for progression and a second population that has more aggressive behaviors and poor prognosis (Guerra et al. 2012a). Currently, for low-risk PTMC cases which are often incidentally detected by imaging studies, such as ultrasound screening, limited treatment with appropriate clinical monitoring without aggressive interventions is considered to be a reasonable therapeutic strategy (Ito \&
Miyauchi 2007, 2009). However, this strategy is not applicable to patients with high-risk characteristics, such as those with extrathyroidal extension, LNM, advanced stages and distant metastasis because these factors are usually associated with aggressive cancer and a poor prognosis (Ito \& Miyauchi 2007, 2009). Both European Thyroid Association (Pacini et al. 2006) and American Thyroid Association guidelines (Cooper et al. 2009) recommended hemithyroidectomy for PTMCs in the absence of preoperative evidence of LNM. Unfortunately, it is often not a straightforward task to identify preoperative LNM in PTMCs because of the limitations associated with ultrasonographic examinations, which diminish the detection sensitivities. Thus, LNM is frequently found during an operation or in the pathology postoperatively, with an incidence reported to be 30-65\% (Guerra et al. 2012a). As in PTC in general, LNM is also associated with tumor recurrence of PTMC as demonstrated in a large meta-analysis (Roti et al. 2008). In order to decrease the overall recurrence rate and possibly improve the survival rate, it would be reasonable to remove metastatic lymph nodes in the neck, which is the most common source of recurrence of PTMC. Thus, if known preoperatively to be associated with LNM, it would be reasonable to treat PTMC with total or near-total thyroidectomy with the appropriate extent of central neck dissection. On the other hand, indiscriminative prophylactic central compartment neck dissection is associated with significant risks of surgical complications such as the damage to the recurrent laryngeal nerve and hypoparathyroidism (Brown et al. 2008, Witt 2008) and should be avoided. Therefore, identification of aggressive PTMC

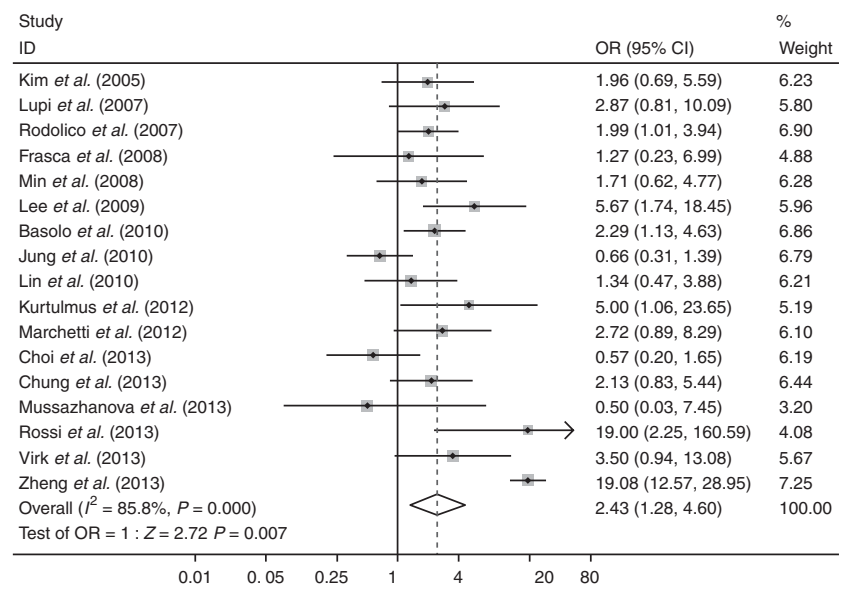

Figure 6

Random effect model of the odds ratios (ORs) with $95 \% \mathrm{Cl}$ of the BRAFV600E mutation associated with lymph node metastasis is shown.

Published by Bioscientifica Ltd. 


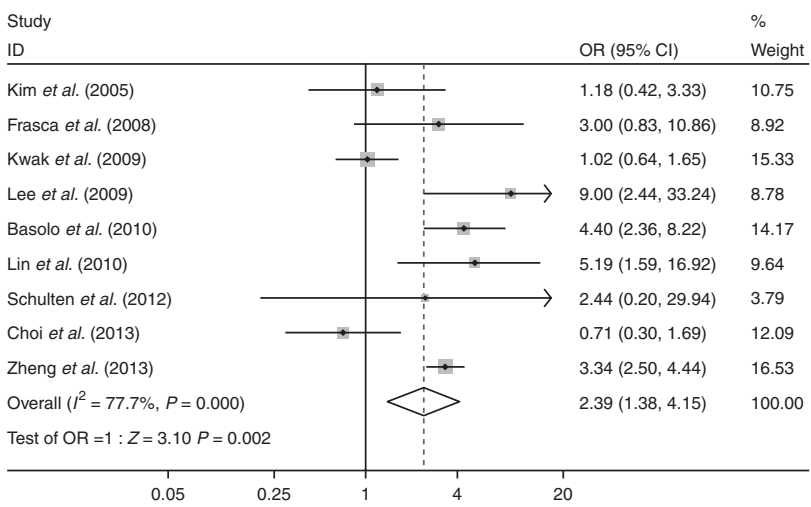

Figure 7

Random effect model of the odds ratios (ORs) with $95 \% \mathrm{Cl}$ of the BRAFV600E mutation associated with the advanced stage (TNM III/IV) is shown.

preoperatively and design of appropriate treatments have become an important yet often challenging issue.

BRAFV600E has provided the promise of better and practically helpful risk stratification for PTC, including PTMC, which can be applied as a prognostic molecular marker for preoperative testing of FNAB specimens (Xing et al. 2009, Joo et al. 2012). Several molecular mechanisms are well known to underly the aggressive role of BRAFV600E. It has been widely demonstrated that the BRAFV600E mutation can promote upregulation of many tumor-promoting genes and downregulation of tumor suppressor genes and aberrant silencing of thyroid iodide-handling genes, impairing the sensitivity of PTC to radioactive iodine treatment (Liu et al. 2007, Xing 2013). These results all indicate that, biologically, the BRAFV600E mutation plays a critical role in the tumorigenesis, progression, and aggressiveness of PTC. This explains well the role of the BRAFV600E mutation in the increased risk of aggressiveness of PTMC positive for this mutation. Given the heterogeneity of BRAF mutation in PTC as indicated by the results of studies by the Vitale group (Guerra et al. 2012a,b) and the recent elegant de Biase study (de Biase et al. 2014), multifocal PTMC lesions may not necessarily harbor $B R A F$ mutations.

As the utility of BRAFV600E mutation assessment in the management of PTC has been increasingly appreciated (Xing 2007, 2013, Kim et al. 2012, Xing et al. 2013a), mutational analysis may also be useful in the preoperative management of patients with PTMC. In this metaanalysis, we found a strongly significant association of BRAFV600E mutation with extrathyroidal invasion, multifocality, LNM, and advanced disease stages of PTMC, confirming that the presence of BRAFV600E is a risk for increased aggressiveness of PTMC. Therefore, BRAFV600E may be a useful prognostic molecular marker to help identify PTMCs with increased risk of aggressive clinicopathological behaviors, including LNM and hence increased risk of disease recurrence. Xing et al. (2013b) carried out a study of 1849 patients to investigate the association between BRAFV600E and PTC-related mortality and found that the BRAFV600E mutation was significantly associated with increased cancer-related mortality among patients with PTC compared with the WT BRAF group. Many studies on PTC have also demonstrated a strong association between the BRAFV600E mutation and tumor recurrence (e.g., Xing et al. 2005, 2014, Elisei et al. 2012). There have been few studies that have assessed the relationship between patient survival or tumor recurrence of PTMC and the BRAFV600E mutation, and no reliable conclusions could be reached due to the relatively small number of cases in most studies. Subgroup analyses in two recent large multicenter studies demonstrated a significant association of the BRAFV600E mutation with tumor recurrence and patient mortality in PTMC (Xing et al. 2013b, 2014). However, larger studies could be even more helpful to definitively address the role of BRAFV600E in tumor recurrence and patient mortality of PTMC.

Table 2 Subgroup analyses of the effects of BRAFV600E mutation on the aggressive clinicopathological features of PTMC according to country

\begin{tabular}{|c|c|c|c|}
\hline Subgroup & $\begin{array}{c}\text { Total } \\
\text { no. of } \\
\text { patients }\end{array}$ & OR $(95 \% \mathrm{Cl})$ & $I^{2}(0$ \\
\hline \multicolumn{4}{|l|}{ Multifocality } \\
\hline Korea (three studies) & 500 & $1.54(1.02-2.32)$ & 0 \\
\hline Italy (four studies) & 996 & $1.26(0.84-1.90)$ & 34.8 \\
\hline China (two studies) & 1038 & $1.78(0.42-7.55)$ & 81.7 \\
\hline Turkey (one study) & 64 & $2.75(0.91-8.27)$ & 0 \\
\hline \multicolumn{4}{|l|}{ Extrathyroidal extension } \\
\hline Korea (two studies) & 161 & $1.09(0.56-2.12)$ & 0 \\
\hline Italy (five studies) & 1046 & $3.64(2.59-5.12)$ & 0 \\
\hline China (three studies) & 1102 & $3.97(2.46-6.40)$ & 19.7 \\
\hline Others (two studies) & 77 & $2.90(0.70-12.00)$ & 0 \\
\hline \multicolumn{4}{|l|}{ Lymph node metastasis } \\
\hline Korea (five studies) & 479 & $1.18(0.67-2.08)$ & 43.4 \\
\hline Italy (five studies) & 1046 & $2.65(1.56-4.50)$ & 6. \\
\hline China (three studies) & 1102 & $5.52(1.02-29.91)$ & 91.2 \\
\hline USA (two studies) & 301 & $2.24(1.23-4.11)$ & 0 \\
\hline Others (two studies) & 77 & $2.08(0.23-18.79)$ & 52.7 \\
\hline \multicolumn{4}{|l|}{ Advanced stage } \\
\hline Korea (three studies) & 500 & $0.97(0.66-1.43)$ & 0 \\
\hline China (three studies) & 1102 & $3.98(2.48-6.37)$ & 20.7 \\
\hline Italy (two studies) & 679 & $4.09(2.34-7.17)$ & 0 \\
\hline Saudi Arabia (one study) & 56 & $2.44(0.20,29.94)$ & 0 \\
\hline
\end{tabular}

Published by Bioscientifica Ltd. 
Although cancer-related mortality rate among patients with PTMC is extremely low, recurrence is relatively common and occurs in $4.0-13.4 \%$ of patients (Davies et al. 2002, Ross et al. 2009, Joo et al. 2012, Tufano et al. 2012), which is associated with an increase of fivefold in the risk of cancer-related death (Liu et al. 2007). Therefore, Xing (2009) suggested that the primary management goal for this cancer is to prevent its progression and to identify, prevent, and manage its recurrence. To this end, more aggressive treatment of $B R A F$-mutation-positive PTMC in appropriate clinical settings may be reasonable. This seems to be the case particularly in areas where the prevalence of BRAFV600E was low. In contrast, BRAFV600E may have relatively limited prognostic utility in areas, such as Korea, where the BRAFV600E mutation has an extremely high prevalence (Jung et al. 2010, Choi et al. 2013, Chung et al. 2013).

\section{Conclusion}

In conclusion, the results of this large meta-analysis demonstrate that the BRAFV600E mutation is strongly associated with aggressive clinicopathologic behaviors of PTMC, including extrathyroidal extension, LNM, and advanced stage. The BRAFV600E mutation may prove to be a useful prognostic molecular marker in assisting the risk stratification and management of PTMC in appropriately defined clinical settings.

\section{Declaration of interest}

The authors declare that there is no conflict of interest that could be perceived as prejudicing the impartiality of the research reported.

\section{Funding}

This work was supported by Chinese Medical Society Clinical grant numbers 12020550355 and 13020260411 and the Chinese National Science Foundation grant number 81472579 .

\section{References}

Basolo F, Torregrossa L, Giannini R, Miccoli M, Lupi C, Sensi E, Berti P, Elisei R, Vitti P, Baggiani A et al. 2010 Correlation between the BRAF V600E mutation and tumor invasiveness in papillary thyroid carcinomas smaller than 20 millimeters: analysis of 1060 cases. Journal of Clinical Endocrinology and Metabolism 95 4197-4205. (doi:10.1210/jc. 2010-0337)

de Biase D, Cesari V, Visani M, Casadei GP, Cremonini N, Gandolfi G, Sancisi V, Ragazzi M, Pession A, Ciarrocchi A et al. 2014 High-sensitivity $B R A F$ mutation analysis: $B R A F$ V600E is acquired early during tumor development but is heterogeneously distributed in a subset of papillary thyroid carcinomas. Journal of Clinical Endocrinology and Metabolism 99 E1530-E1538. (doi:10.1210/jc.2013-4389)

Brown AP, Chen J, Hitchcock YJ, Szabo A, Shrieve DC \& Tward JD 2008 The risk of second primary malignancies up to three decades after the treatment of differentiated thyroid cancer. Journal of Clinical Endocrinology and Metabolism 93 504-515. (doi:10.1210/jc.2007-1154)

Choi SY, Park H, Kang MK, Lee DK, Lee KD, Lee HS, Kim SW, Lee EN \& Hong JC 2013 The relationship between the $\mathrm{BRAF}^{\mathrm{V} 600 \mathrm{E}}$ mutation in papillary thyroid microcarcinoma and clinicopathologic factors. World Journal of Surgical Oncology 11 291. (doi:10.1186/1477-7819-11-291)

Chung SY, Lee JS, Lee H, Park SH, Kim SJ \& Ryu HS 2013 Cytomorphological factors and BRAF mutation predicting risk of lymph node metastasis in preoperative liquid-based fine needle aspirations of papillary thyroid carcinoma. Acta Cytologica 57 252-258. (doi:10.1159/ 000343617)

Cooper DS, Doherty GM, Haugen BR, Kloos RT, Lee SL, Mandel SJ, Mazzaferri EL, McIver B, Pacini F, Schlumberger M et al. 2009 Revised American Thyroid Association management guidelines for patients with thyroid nodules and differentiated thyroid cancer. Thyroid 19 1167-1214. (doi:10.1089/thy.2009.0110)

Davies L \& Welch HG 2006 Increasing incidence of thyroid cancer in the United States, 1973-2002. Journal of the American Medical Association 295 2164-2167. (doi:10.1001/jama.295.18.2164)

Davies H, Bignell GR, Cox C, Stephens P, Edkins S, Clegg S, Teague J, Woffendin H, Garnett MJ, Bottomley W et al. 2002 Mutations of the BRAF gene in human cancer. Nature 417 949-954. (doi:10.1038/ nature00766)

Elisei R, Viola D, Torregrossa L, Giannini R, Romei C, Ugolini C, Molinaro E, Agate L, Biagini A, Lupi C et al. 2012 The $B R A F^{\mathrm{V} 600 \mathrm{E}}$ mutation is an independent, poor prognostic factor for the outcome of patients with low-risk intrathyroid papillary thyroid carcinoma: single-institution results from a large cohort study. Journal of Clinical Endocrinology and Metabolism 97 4390-4398. (doi:10.1210/jc.2012-1775)

Frasca F, Nucera C, Pellegriti G, Gangemi P, Attard M, Stella M, Loda M, Vella V, Giordano C, Trimarchi F et al. $2008 B R A F^{\mathrm{V} 600 \mathrm{E}}$ mutation and the biology. Endocrine-Related Cancer 15 191-205. (doi:10.1677/ ERC-07-0212)

Guerra A, Fugazzola L, Marotta V, Cirillo M, Rossi S, Cirello V, Forno I, Moccia T, Budillon A \& Vitale M 2012a A high percentage of $B R A F^{\mathrm{V} 600 \mathrm{E}}$ alleles in papillary thyroid carcinoma predicts a poorer outcome. Journal of Clinical Endocrinology and Metabolism 97 2333-2340. (doi:10.1210/jc.2011-3106)

Guerra A, Sapio MR, Marotta V, Campanile E, Rossi S, Forno I, Fugazzola L, Budillon A, Moccia T, Fenzi G et al. 2012b The primary occurrence of $B R A F^{\mathrm{V} 600 \mathrm{E}}$ is a rare clonal event in papillary thyroid carcinoma. Journal of Clinical Endocrinology and Metabolism 97 517-524. (doi:10.1210/jc.2011-0618)

Higgins JP, Thompson SG, Deeks JJ \& Altman DG 2003 Measuring inconsistency in meta-analyses. BMJ 327 557-560. (doi:10.1136/bmj. 327.7414.557)

Hughes DT, Haymart MR, Miller BS, Gauger PG \& Doherty GM 2011 The most commonly occurring papillary thyroid cancer in the United States is now a microcarcinoma in a patient older than 45 years. Thyroid $\mathbf{2 1}$ 231-236. (doi:10.1089/thy.2010.0137)

Ito Y \& Miyauchi A 2007 A therapeutic strategy for incidentally detected papillary microcarcinoma of the thyroid. Nature Clinical Practice. Endocrinology \& Metabolism 3 240-248. (doi:10.1038/ncpendmet0428)

Ito Y \& Miyauchi A 2009 Prognostic factors and therapeutic strategies for differentiated carcinomas of the thyroid. Endocrine Journal 56 177-192. (doi:10.1507/endocrj.K08E-166)

Joo JY, Park JY, Yoon YH, Choi B, Kim JM, Jo YS, Shong M \& Koo BS 2012 Prediction of occult central lymph node metastasis in papillary thyroid carcinoma by preoperative $B R A F$ analysis using fine-needle aspiration biopsy: a prospective study. Journal of Clinical Endocrinology and Metabolism 97 3996-4003. (doi:10.1210/jc.2012-2444) 
Jung CK, Kang YG, Bae JS, Lim DJ, Choi YJ \& Lee KY 2010 Unique patterns of tumor growth related with the risk of lymph node metastasis in papillary thyroid carcinoma. Modern Pathology 23 1201-1208. (doi:10.1038/modpathol.2010.116)

Kim TY, Kim WB, Song JY, Rhee YS, Gong G, Cho YM, Kim SY, Kim SC, Hong SJ \& Shong YK 2005 The $B R A F^{\mathrm{V} 600 \mathrm{E}}$ mutation is not associated with poor prognostic factors in Korean patients with conventional papillary thyroid microcarcinoma. Clinical Endocrinology 63 588-593. (doi:10.1111/j.1365-2265.2005.02389.x)

Kim TH, Park YJ, Lim JA, Ahn HY, Lee EK, Lee YJ, Kim KW, Hahn SK, Youn YK, Kim KH et al. 2012 The association of the BRAF $F^{\mathrm{V} 600 \mathrm{E}}$ mutation with prognostic factors and poor clinical outcome in papillary thyroid cancer: a meta-analysis. Cancer 118 1764-1773. (doi:10.1002/cncr.26500)

Kurtulmus N, Duren M, Ince U, Cengiz Yakicier M, Peker O, Aydin O, Altiok E, Giray S \& Azizlerli H $2012 \mathrm{BRAF}^{\mathrm{V} 600 \mathrm{E}}$ mutation in Turkish patients with papillary thyroid cancer: strong correlation with indicators of tumor aggressiveness. Endocrine 42 404-410. (doi:10.1007/s12020-012-9651-x)

Kwak JY, Kim EK, Chung WY, Moon HJ, Kim MJ \& Choi JR 2009 Association of $\mathrm{BRAF}^{\mathrm{V} 600 \mathrm{E}}$ mutation with poor clinical prognostic factors and US features in Korean patients with papillary thyroid microcarcinoma. Radiology 253 854-860. (doi:10.1148/radiol. 2533090471)

Lee X, Gao M, Ji Y, Yu Y, Feng Y, Li Y, Zhang Y, Cheng W \& Zhao W 2009 Analysis of differential $\mathrm{BRAF}^{\mathrm{V} 600 \mathrm{E}}$ mutational status in high aggressive papillary thyroid microcarcinoma. Annals of Surgical Oncology 16 240-245. (doi:10.1245/s10434-008-0233-3)

Lin KL, Wang OC, Zhang XH, Dai XX, Hu XQ \& Qu JM 2010 The BRAF mutation is predictive of aggressive clinicopathological characteristics in papillary thyroid microcarcinoma. Annals of Surgical Oncology $\mathbf{1 7}$ 3294-3300. (doi:10.1245/s10434-010-1129-6)

Liu D, Liu Z, Condouris S \& Xing M 2007 BRAF V600E maintains proliferation, transformation, and tumorigenicity of BRAF-mutant papillary thyroid cancer cells. Journal of Clinical Endocrinology and Metabolism 92 2264-2271. (doi:10.1210/jc.2006-1613)

LiVolsi VA, Albores-Saavedra J, Asa SL, Baloch ZW, Sobrinho-Simőes M, Wenig B. 2004 Papillary carcinoma. In: Pathology and Genetics of Tumours of Endocrine Organs. World Health Organization Classification of Tumours, vol 8, pp 57-66. Eds RA DeLellis, RV Lloyd, PU Heitz \& C Eng. Lyon, France: IARC Press.

Lupi C, Giannini R, Ugolini C, Proietti A, Berti P, Minuto M, Materazzi G, Elisei R, Santoro M, Miccoli P et al. 2007 Association of BRAF V600E mutation with poor clinicopathological outcomes in 500 consecutive cases of papillary thyroid carcinoma. Journal of Clinical Endocrinology and Metabolism 92 4085-4090. (doi:10.1210/jc.2007-1179)

Marchetti I, Iervasi G, Mazzanti CM, Lessi F, Tomei S, Naccarato AG, Aretini P, Alberti B, Di Coscio G \& Bevilacqua G 2012 Detection of the $B R A F^{\mathrm{V} 600 \mathrm{E}}$ mutation in fine needle aspiration cytology of thyroid papillary microcarcinoma cells selected by manual macrodissection: an easy tool to improve the preoperative diagnosis. Thyroid 22 292-298. (doi:10.1089/thy.2011.0107)

Mathur A, Weng J, Moses W, Steinberg SM, Rahbari R, Kitano M, Khanafshar E, Ljung BM, Duh QY, Clark OH et al. 2010 A prospective study evaluating the accuracy of using combined clinical factors and candidate diagnostic markers to refine the accuracy of thyroid fine needle aspiration biopsy. Surgery 148 1170-1176 discussion 1176-1177. (doi:10.1016/j.surg.2010.09.025)

Min HS, Choe G, Kim SW, Park YJ, Park do J, Youn YK, Park SH, Cho BY \& Park SY 2008 S100A4 expression is associated with lymph node metastasis in papillary microcarcinoma of the thyroid. Modern Pathology 21 748-755. (doi:10.1038/modpathol.2008.51)

Moses W, Weng J, Sansano I, Peng M, Khanafshar E, Ljung BM, Duh QY, Clark OH \& Kebebew E 2010 Molecular testing for somatic mutations improves the accuracy of thyroid fine-needle aspiration biopsy. World Journal of Surgery 34 2589-2594. (doi:10.1007/s00268010-0720-0)

Mussazhanova Z, Matsuda K, Naruke Y, Mitsutake N, Stanojevic B, Rougounovitch T, Saenko V, Suzuki K, Nishihara E, Hirokawa M et al. 2013 Significance of p53-binding protein 1 (53BP1) expression in thyroid papillary microcarcinoma: association with $B R A F^{\mathrm{V} 600 \mathrm{E}}$ mutation status. Histopathology 63 726-734. (doi:10.1111/his.12233)

Pacini F, Schlumberger M, Dralle H, Elisei R, Smit JW, Wiersinga W \& European Thyroid Cancer Taskforce 2006 European consensus for the management of patients with differentiated thyroid carcinoma of the follicular epithelium. European Journal of Endocrinology 154 787-803. (doi:10.1530/eje.1.02158)

Ries LAG, Melbert D, Krapcho M, Mariotto A, Miller BA, Feuer EJ, Clegg L, Horner MJ, Howlader N, Eisner MP, Reichman M, Edwards BK (Eds) 2007 SEER Cancer Statistics Review, 1975-2004 (based on the November 2006 SEER data submission, posted to the SEER web site 2007), available at: http://seer.cancer.gov/csr/1975_2004/ [accessed June 1, 2010].

Rodolico V, Cabibi D, Pizzolanti G, Richiusa P, Gebbia N, Martorana A, Russo A, Amato MC, Galluzzo A \& Giordano C 2007 BRAF $F^{\mathrm{V} 600 \mathrm{E}}$ mutation and $\mathrm{p} 27^{\mathrm{kip} 1}$ expression in papillary carcinomas of the thyroid $<$ or $=1 \mathrm{~cm}$ and their paired lymph node metastases. Cancer $\mathbf{1 1 0}$ 1218-1226. (doi:10.1002/cncr.22912)

Ross DS, Litofsky D, Ain KB, Bigos T, Brierley JD, Cooper DS, Haugen BR, Jonklaas J, Ladenson PW, Magner J et al. 2009 Recurrence after treatment of micropapillary thyroid cancer. Thyroid 19 1043-1048. (doi:10.1089/thy.2008.0407)

Rossi ED, Martini M, Capodimonti S, Lombardi CP, Pontecorvi A, Vellone VG, Zannoni GF, Larocca LM \& Fadda G 2013 BRAF (V600E) mutation analysis on liquid-based cytology-processed aspiration biopsies predicts bilaterality and lymph node involvement in papillary thyroid microcarcinoma. Cancer Cytopathology 121 291-297. (doi:10.1002/cncy.21258)

Roti E, degli Uberti EC, Bondanelli M \& Braverman LE 2008 Thyroid papillary microcarcinoma: a descriptive and meta-analysis study. European Journal of Endocrinology 159 659-673. (doi:10.1530/EJE07-0896)

Schulten HJ, Salama S, Al-Mansouri Z, Alotibi R, Al-Ghamdi K, Al-Hamour OA, Sayadi H, Al-Aradati H, Al-Johari A, Huwait E et al. 2012 BRAF mutations in thyroid tumors from an ethnically diverse group. Hereditary Cancer in Clinical Practice 10 10. (doi:10.1186/18974287-10-10)

Tufano RP, Teixeira GV, Bishop J, Carson KA \& Xing M 2012 BRAF mutation in papillary thyroid cancer and its value in tailoring initial treatment: a systematic review and meta-analysis. Medicine 91 274-286. (doi:10.1097/MD.0b013e31826a9c71)

Virk RK, Van Dyke AL, Finkelstein A, Prasad A, Gibson J, Hui P, Theoharis CG, Carling T, Roman SA, Sosa JA et al. $2013 B R A F^{\mathrm{V} 600 \mathrm{E}}$ mutation in papillary thyroid microcarcinoma: a genotype-phenotype correlation. Modern Pathology 26 62-70. (doi:10.1038/modpathol.2012.152)

Witt RL 2008 Initial surgical management of thyroid cancer. Surgical Oncology Clinics of North America 17 71-91 viii. (doi:10.1016/j.soc.2007. 10.010)

Xing M 2005 BRAF mutation in thyroid cancer. Endocrine-Related Cancer 12 245-262. (doi:10.1677/erc.1.0978)

Xing M 2007 BRAF mutation in papillary thyroid cancer: pathogenic role, molecular bases, and clinical implications. Endocrine Reviews $\mathbf{2 8}$ 742-762. (doi:10.1210/er.2007-0007)

Xing M 2009 BRAF mutation in papillary thyroid microcarcinoma: the promise of better risk management. Annals of Surgical Oncology 16 801-803. (doi:10.1245/s10434-008-0298-z)

Xing M 2013 Molecular pathogenesis and mechanisms of thyroid cancer. Nature Reviews. Cancer 13 184-199. (doi:10.1038/nrc3431)

Xing M, Westra WH, Tufano RP, Cohen Y, Rosenbaum E, Rhoden KJ, Carson KA, Vasko V, Larin A, Tallini G et al. 2005 BRAF mutation predicts a poorer clinical prognosis for papillary thyroid cancer. 
Journal of Clinical Endocrinology and Metabolism 90 6373-6379. (doi:10.1210/jc.2005-0987)

Xing M, Clark D, Guan H, Ji M, Dackiw A, Carson KA, Kim M, Tufaro A, Ladenson P, Zeiger M et al. 2009 BRAF mutation testing of thyroid fineneedle aspiration biopsy specimens for preoperative risk stratification in papillary thyroid cancer. Journal of Clinical Oncology 27 2977-2982. (doi:10.1200/JCO.2008.20.1426)

Xing M, Haugen BR \& Schlumberger M 2013a Progress in molecular-based management of differentiated thyroid cancer. Lancet 381 1058-1069. (doi:10.1016/S0140-6736(13)60109-9)

Xing M, Alzahrani AS, Carson KA, Viola D, Elisei R, Bendlova B, Yip L, Mian C, Vianello F, Tuttle RM et al. 2013b Association between BRAF
V600E mutation and mortality in patients with papillary thyroid cancer. Journal of the American Medical Association 309 1493-1501. (doi:10.1001/jama.2013.3190)

Xing M, Alzahrani AS, Carson KA, Shong YK, Kim TY, Viola D, Elisei R, Bendlova B, Yip L, Mian C et al. 2014 Association between $B R A F \mathrm{~V} 600 \mathrm{E}$ mutation and recurrence of papillary thyroid cancer. Journal of Clinical Oncology 33 42-50. (doi:10.1200/JCO.2014. 56.8253)

Zheng X, Wei S, Han Y, Li Y, Yu Y, Yun X, Ren X \& Gao M 2013 Papillary microcarcinoma of the thyroid: clinical characteristics and $\mathrm{BRAF}^{\mathrm{V} 600 \mathrm{E}}$ mutational status of 977 cases. Annals of Surgical Oncology 20 2266-2273. (doi:10.1245/s10434-012-2851-z)

Received in final form 4 January 2015

Accepted 12 January 2015

Made available online as an Accepted Preprint

15 January 2015
Published by Bioscientifica Ltd. 